\title{
TAGUCHI OPTIMIZATION FOR EFFICIENT EXTRACTION OF A NATURAL DYE FROM BOUGAINVILLEA GLABRA BRACTS
}

\author{
Pravinkumar.D. Patil ${ }^{1}$, C.R. Rao ${ }^{2}$, A.I. Wasif ${ }^{3}$, J.R.Nagla ${ }^{4}$ \\ ${ }^{1}$ Assistant Professor and Corresponding author, Department of Technology, Shivaji University, Kolhapur, Maharashtra, \\ India. \\ ${ }^{2}$ Director Evaluations, Vigyan University, Vadlamudi, Guntur, Andhra Pradesh, India \\ ${ }^{3}$ Professor, Textile and Engineering Institute, DKTES, Ichalkaranji, Maharashtra, India \\ ${ }^{4}$ Associate Professor, Textile and Engineering Institute, DKTES, Ichalkaranji, Maharashtra, India
}

\begin{abstract}
Dyes are used for various purposes such as coloration of textiles, foodstuffs, leather tanning. These are also used for cosmetic, pharmaceutical and photovoltaic applications. The synthetic dyes are today's established materials for all these applications. However due to environmental and human health related issues, a major group of the synthetic dyes is proven to be dangerous. Eventually, at this stage of civilization, natural dyes are one of the alternatives to these synthetic dyes. Besides this, in the past few decades, recent trend is seen to use products from natural resources in all the possible fields. Dyes obtained from natural sources are among such important products. One major challenge in upbringing these natural but old dyes is the drawback of incomplete dye extraction from their source. This research mainly focuses on extraction optimization of a natural dye from bracts of a shrub 'Bougainvillea Glabra'. Taguchi technique was used for the optimization process. The results showed that 150 micron particle size, 1:20 solid-solvent ratio, one hour extraction and enzyme addition as assistance were the optimum conditions for extraction. The optimum and control extractions results were compared. The respective absorbance values were 0.255 and 0.280 . It was encouraging to observe $9.88 \%$ of increase in the dye yield. Yield improvement in the optimized extraction indicated enhancement in the extraction efficiency. Besides efficient extraction, the research featured the successful implementation of two important green chemistry principles namely 'improving atom economy' and 'use of natural renewable material resources'.
\end{abstract}

Keywords: Taguchi optimization, natural dye, extraction efficiency

\section{INTRODUCTION}

In the ancient times, natural dyes were used for various purposes such as coloration of clothing, food, leather tanning, painting etc. Natural dyes are the colorants extracted from vegetative matter and animal residues. These are obtained from root, leaf, bark, trunk, fruit and flower of plants. These are also derived from animal source such as cochineal and shellfish or sometimes from mineral origin e.g. soils or clay. However by the mid-1800's chemists and others began producing synthetic substitutes for them. By the early part of this century, only a small percentage of textile dyes were extracted from plants. Presently, market is fully dominated by the synthetic dyes because of their vast and easy production giving variety of colors with very good fastness properties. [1]

The history of dyestuff industry depicts that, natural dyes had been in use for thousands of years while the synthetic substitutes have been in use for mere 150 years. Such a short span of time has revealed some serious drawbacks of these synthetic dyes. Ecology and environment problems related to synthetic dyes have increased public awareness. Therefore natural dyes are gaining good popularity. [2] These dyes offer not only variation of dyestuff source but also these have a far superior aesthetic quality which is pleasing to the eye due to unique natural color. Better biodegradability, non-toxic and eco-friendly properties of these dyes over synthetic dyes make them so popular among nature loving and health conscious people around the world. The other benefit of using natural dyes is that it significantly cuts down the amount of toxic effluent resulting from the synthetic dye processes.[3] Vegetative matter is a major natural resource to obtain these dyes. As against synthetic dyes derived from non renewable resources, natural dye is from an excellent renewable resource if proper cultivation of such vegetable kingdom is executed.

In spite of all positive aspects of natural dyes, the present international consumption of natural dyes is just $1 \%$ of the synthetic dye. The main difficulty in upbringing natural dyes is the existing limitations and technical drawbacks of these dyes. Some of these drawbacks are color yield; complexity of dyeing process, limited shades, reproducible results, blending problems and inadequate fastness properties. [4]

Technical drawbacks and limitations of these dyes can be solved through adequate scientific research efforts. However, great challenge is to increase the yield of these dyes. Present 
research work has been carried out to address this issue. It is through optimization of extraction process to get maximum possible quantity of dye from Bougainvillea Glabra Bracts. Here, Taguchi Orthogonal Array, a robust experimental design is employed for optimization. [5]

\section{MATERIALS AND EQUIPMENTS}

\subsection{Raw Material for Dye Extraction}

Bougainvillea is a genus of flowering plants native to South America from Brazil west to Peru and south to southern Argentina. It also grows in tropical and sub tropical forests in India. It is also found in both rural and urban parts of India. It is a popular woody shrub that grows to the height of 10-15 feet and is sometimes referred to as paper flower because the bracts are thin and papery. (Figure 1)

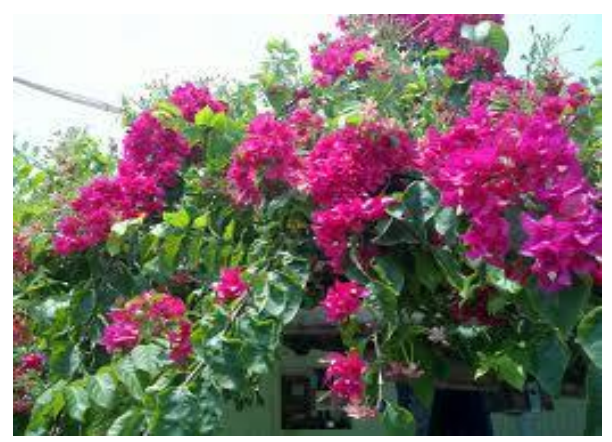

Fig 1: Bougainvillea flowers

These bracts are classic red, purple, orange, white, pink and cream, which bloom all over the year. [6] Scientific classification of the plant is as below:

- Scientific name: Bougainvillea Glabra

- Kingdom:Plantae

- Order:Caryophyllales

- Family:Nyctaginaceae

- Tribe:Bougainvilleeae

- Genus: Bougainvillea

\subsubsection{Raw Material Preparation}

The bracts as the raw dyestuff were collected from the road side shrubs and climbers. Pink colored bracts separated from their branches were dried in a tray dryer. The dry bracts mass was ground in a domestic mixer-grinder giving mixed particle sizes. The powder was sieved to get three different sizes of the dyestuff required for experimental work.

\subsection{Chemicals and Equipments Used}

- Cellulase and pectinase enzymes: HIMEDIA

- $\quad 9.5 \mathrm{P}^{\mathrm{H}}$ Buffer tablets: Merck

- Weighing balance : Shimadzu AUX220

- Domestic microwave oven: Samsung DE68-02233G
- Orbital Shaker-incubator: Nanolab India Model NLSIC-23\#25/50

- Syringe and holder assembly with nylon membrane filters ( 0.2 micron porosity): HIMEDIA

- UV-VIS Spectrophotometer: Shimadzu, Germany, Model UV1800

\subsection{Taguchi Design of Experiment}

Design of Experiment is a powerful statistical technique for improving product or process designs and solving production problems. Its standardized version forwarded by Dr. Genichi Taguchi, allows one to easily learn and apply the technique for product design optimization and production problem investigation. Since its introduction in the U.S.A. in early 1980 's, the approach has been popular as 'product and process improvement tool' in the hands of the engineering and scientific professionals. [7] Taguchi method is mainly used to achieve efficient extraction of dye and to significantly reduce the number of experimental trials. The control factors shown in Table 1 include: raw dyestuff particle size, solid-solvent ratio, extraction time and method of assistance for extraction.

L9 orthogonal arrays selected for the experiments had 9 experimental runs with 4 factors and 3 levels. $[8,9]$ Each of the nine runs was conducted in duplicate. The other parameters ascertained from the literature survey include: Extraction temperature: $600 \mathrm{C}$, Speed of the orbital shaker: 150 $\mathrm{rpm}$, microwave power and irradiation time: $300 \mathrm{Watt}$ and 40 second respectively, enzymes proportion: $2 \%$ of cellulase and $1 \%$ pectinase both on weight of raw dyestuff basis. [10,11] The other important aspect of this work was use of water as solvent. The actual orthogonal array design has been depicted in Table 2 with absorbance value as the response variable.

The control experiment was also conducted simultaneously with the array runs. It was aimed to compare control extraction performance with that of optimized extraction. The absorbances values in the two experiments are were found out.

\section{STATISTICAL DATA ANALYSIS IN EXTRACTION OPTIMIZATION}

The General Linear Model (GLM) was used to perform analysis of variance with balanced and unbalanced designs, analysis of covariance, for the response variable. Calculations were performed using a regression approach. A full rank design matrix is formed from the factors and covariates and the response variable was regressed on the columns of the design matrix. [12] Using Minitab software, analysis was conducted for the response variable namely absorbance. (Table 3 and Table 4)

\subsection{Determination of Dye Yield}

The absorbance value as response variable in the extraction optimization experiment was found out by using the UV-VIS 
Spectrophotometer. To find out the concentration of the dye extracted, the dye powder obtained from the spray drier was used to prepare solutions of different concentrations. The dye concentrations $0.1,0.2,0.3,0.4$ and 0.5 gram $/$ lit were plotted against the respective absorbance values $0.02,0.03,0.05,0.08$ and 0.09. The graph showed the BEST-FIT line. (Figure 3)
The slope of this line is the product of the path length and the molar extinction coefficient. By using slope and the absorbance, the concentration and finally the yield were determined. The yields for the control extraction and optimum extraction were compared.

Table 1: The control factors and levels

\begin{tabular}{|c|c|c|c|}
\hline Factor $\downarrow$ Level $\rightarrow$ & 0 & 1 & 2 \\
\hline Particle size, microns & 150 & 300 & 400 \\
\hline Solid: liquid ratio, g:ml & $1: 10$ & $1: 20$ & $1: 30$ \\
\hline Time, min & 60 & 120 & 180 \\
\hline Method & $\begin{array}{c}\text { Microwave } \\
\text { assistance }\end{array}$ & $\begin{array}{c}\text { Enzyme } \\
\text { assistance }\end{array}$ & $\begin{array}{c}\text { Microwave+ } \\
\text { Enzyme } \\
\text { Assistance }\end{array}$ \\
\hline
\end{tabular}

Table 2: Taguchi Orthogonal Array Design

\begin{tabular}{|c|c|c|c|c|c|}
\hline Factor $\rightarrow$ & \multicolumn{4}{|l|}{ Levels } & \multirow{2}{*}{$\begin{array}{l}\text { Response } \\
\text { Absorbance } \\
\text { At } \lambda_{\max } 272 \mathrm{~nm}\end{array}$} \\
\hline $\begin{array}{l}\text { Experimenta } \\
\text { 1 Run } \downarrow\end{array}$ & Particle Size & $\begin{array}{l}\text { Solid-Liquid } \\
\text { Ratio }\end{array}$ & Time & $\begin{array}{l}\text { Method of } \\
\text { Assistance }\end{array}$ & \\
\hline 1. & 0 & 0 & 0 & 0 & 0.252 \\
\hline 2. & 0 & 1 & 1 & 1 & 0.218 \\
\hline 3. & 0 & 2 & 2 & 2 & 0.230 \\
\hline 4. & 1 & 0 & 1 & 2 & 0.230 \\
\hline 5. & 1 & 1 & 2 & 0 & 0.133 \\
\hline 6. & 1 & 2 & 0 & 1 & 0.182 \\
\hline 7. & 2 & 0 & 2 & 1 & 0.269 \\
\hline 8. & 2 & 1 & 0 & 2 & 0.218 \\
\hline 9. & 2 & 2 & 1 & 0 & 0.194 \\
\hline 10 & 0 & 0 & 0 & 0 & 0.254 \\
\hline 11 & 0 & 1 & 1 & 1 & 0.222 \\
\hline 12 & 0 & 2 & 2 & 2 & 0.231 \\
\hline 13 & 1 & 0 & 1 & 2 & 0.230 \\
\hline 14 & 1 & 1 & 2 & 0 & 0.132 \\
\hline 15 & 1 & 2 & 0 & 1 & 0.182 \\
\hline 16 & 2 & 0 & 2 & 1 & 0.268 \\
\hline 17 & 2 & 1 & 0 & 2 & 0.218 \\
\hline 18 & 2 & 2 & 1 & 0 & 0.193 \\
\hline Control & Coarse & $1: 20$ & $\begin{array}{l}3 \text { hours } \\
\text { at boil }\end{array}$ & $\begin{array}{l}\text { No any } \\
\text { assistance }\end{array}$ & 0.255 \\
\hline
\end{tabular}




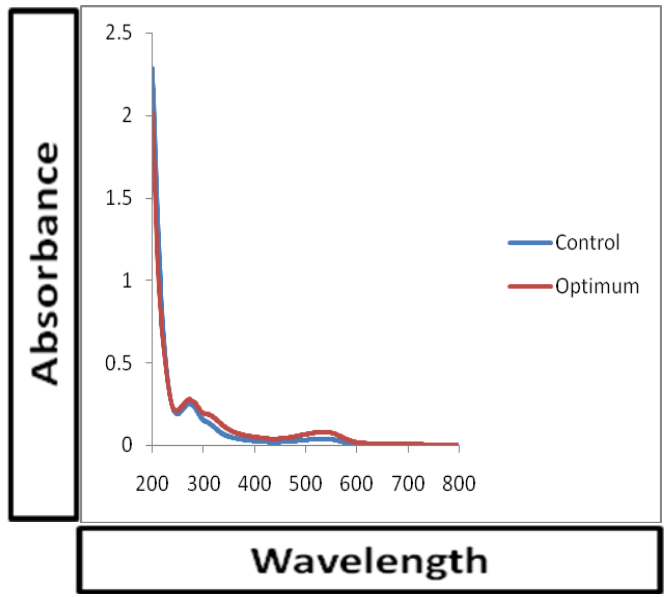

Figure 2: UV-VIS Spectra $\left(\lambda_{\max } 272 \mathrm{~nm}\right)$

Table 3: Analysis of Variance for Absorbance, using Adjusted SS for Tests

\begin{tabular}{|l|l|l|l|l|l|l|}
\hline Source & DF & Seq SS & Adj SS & Adj MS & F & P \\
\hline Replica & 1 & 0.0000 & 0.0000 & 0.0000 & 0.0000 & 1.000 \\
\hline Particle Size & 2 & 0.0831 & 0.0831 & 0.04155 & $1.70 \mathrm{E}+05$ & 0.000 \\
\hline Solid-Liquid ratio & 2 & 0.03498 & 0.03498 & 0.01749 & $7.00 \mathrm{E}+04$ & 0.000 \\
\hline Time of extraction & 2 & 0.0129 & 0.0129 & 0.00645 & $2.60 \mathrm{E}+04$ & 0.000 \\
\hline Method of assistance & 2 & 0.00914 & 0.00914 & 0.00457 & $1.80 \mathrm{E}+04$ & 0.000 \\
\hline Error & 8 & $2 \mathrm{E}-06$ & $2 \mathrm{E}-06$ & 0 & & \\
\hline Total & 17 & 0.14011 & & & & \\
\hline & & & & & & \\
\hline
\end{tabular}

Table 4: Least Squares Means for Absorbance

\begin{tabular}{|l|l|l|l|}
\hline Parameter & Level & Mean & SE Mean \\
\hline Particle Size & 0 & 0.3437 & 0.0002 \\
\cline { 2 - 4 } & 1 & 0.1815 & 0.0002 \\
\cline { 2 - 4 } & 2 & 0.2302 & 0.0002 \\
\hline Solid-Liquid Ratio & 0 & 0.3092 & 0.0002 \\
\cline { 2 - 4 } & 1 & 0.2442 & 0.0002 \\
\cline { 2 - 4 } & 2 & 0.202 & 0.0002 \\
\hline Time of Extraction & 0 & 0.2728 & 0.0002 \\
\cline { 2 - 4 } & 1 & 0.2685 & 0.0002 \\
\cline { 2 - 4 } & 2 & 0.214 & 0.0002 \\
\hline Method of Assistance & 0 & 0.2482 & 0.0002 \\
\cline { 2 - 4 } & 1 & 0.281 & 0.0002 \\
\cline { 2 - 4 } & 2 & 0.2262 & 0.0002 \\
\hline
\end{tabular}




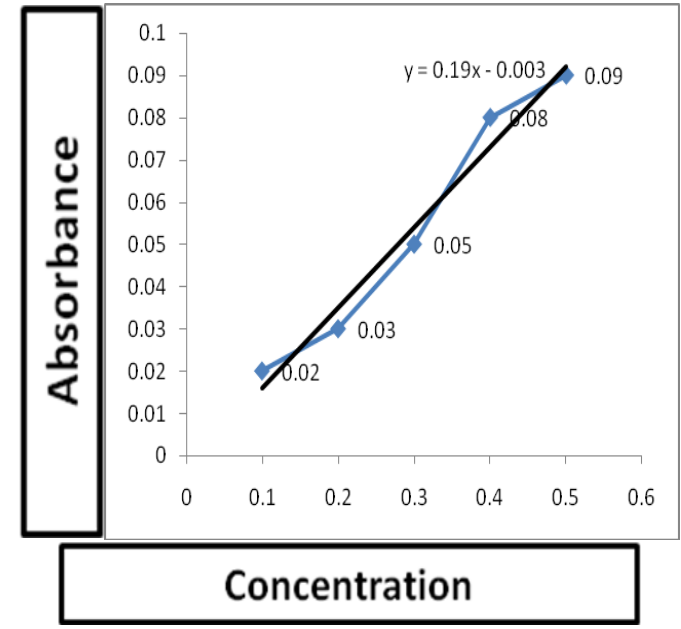

Fig 3: Absorbance v/s Concentration

Beer-Lambert law is a quantitative way to determine concentration of an absorbing species in solution.

$$
A=\log _{10}\left(I_{o} / I\right)=[\varepsilon * L] * c=\text { slope }^{*} c \quad \text { Eq. } 1
$$

Thus,

$$
\begin{array}{ll}
\text { Concentration }=\text { Absorbance/Slope } & \text { Eq.2 } \\
\text { The trend line is } Y=0.19 X-0.003 & \text { Eq.3 }
\end{array}
$$

The concentration values and the molecular mass of predicted colorants were used to calculate dye yields.

\subsection{Control Extraction}

$\mathrm{C}=$ Absorbance $/$ slope $=0.255 / 0.19$

$$
=1.342 \mathrm{moles} / \mathrm{lit} \quad \text { Eq. } 4
$$

$0.5 \mathrm{ml}$ of the original extract was diluted to $100 \mathrm{ml}$ (200 times). Therefore the original concentration was $1.342 * 200=268.42$ moles/lit. The colorant with the molecular weight 551 is present in the extract. Therefore presence of the colorant in the extract is $268.42 / 551=0.4871 \mathrm{gm} /$ lit which is 0.04871 $\mathrm{gm} / 100 \mathrm{ml}$. However, the source of the colorant is from $3 \mathrm{gm}$ of the raw dyestuff.

$\%$ Yield (control) $=$ [color extracted/quantity of raw dyestuff]*100

$$
\begin{aligned}
& =[0.04871 / 3] * 100 \\
& =1.6238
\end{aligned}
$$

Eq.5
$0.5 \mathrm{ml}$ of the original extract was diluted to $100 \mathrm{ml}$ (200 times). Therefore the original concentration was $1.473 * 200$ $=294.73 \mathrm{moles} / \mathrm{lit}$. Therefore presence of the colorant in the extract is $294.73 / 551=0.5349 \mathrm{gm} / \mathrm{lit}$ which is 0.05349 $\mathrm{gm} / 100 \mathrm{ml}$. However, the source of the colorant is from $3 \mathrm{gm}$ of the raw dyestuff.

$\%$ Yield (optimum) $=$

[Color extracted/quantity of raw dyestuff] $* 100$

$$
=[0.05349 / 3] * 100
$$$$
=1.783
$$

\subsection{Extraction Efficiency Enhancement Calculations:}

When control extraction was compared against optimum, the improvement in extraction efficiency was follows:

Extraction efficiency enhancement

$=[$ Yield $($ Optimum-Control) $)] /$ Yield (Control)

$=[1.783-1.62] / 1.62=9.8 \%$

Eq.8

\section{RESULTS AND DISCUSSION}

\subsection{Optimization experiment}

Variance analysis results showed statistical significance of chosen conditions. The F-value for each parameter indicates which parameter has significant effect on extraction and is simply a ratio of the squared deviation to the mean of squared error. Usually, larger F-value shows greater effect on the extraction value due to the change of the process parameter. Optimal combination of process parameters was predicted using ANOVA. (Figure 4)

\subsection{Optimum Extraction:}

$\mathrm{C}=$ Absorbance $/$ slope $=0.280 / 0.19$

$$
=1.473 \text { moles } / \text { lit } \quad \text { Eq. } 6
$$




\section{Main Effects Plot - Data Means for Absorbance}

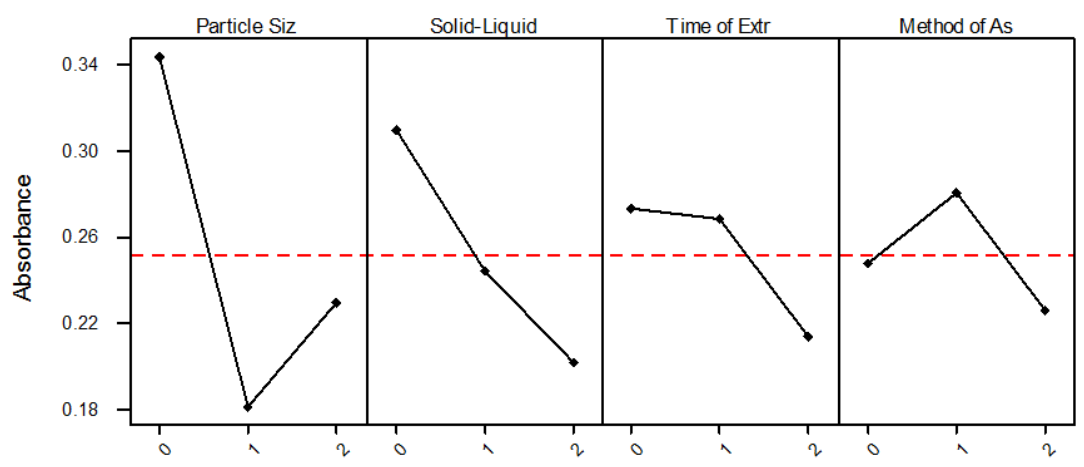

Figure 4: Main Effects Plot

\subsubsection{Effect of Particle Size:}

Amongst the four conditions selected, raw dyestuff particle size was found as the second significant parameter for extraction. The particle sizes 150, 300 and 450 microns were coded as 0,1 and 2. Results indicated the highest value of absorbance (0.3437) for the finest particle size (150 micron). This maximum value is very well above mean absorbance value. Optimum particle size is thus 150 microns. Reason for this may be the highest contact surface area of the finest size thereby increasing the extraction efficiency.

\subsubsection{Effect of Solid-Solvent Ratio:}

Solid-solvent ratio was found as the most significant extraction parameters. Three ratios 1:20, 1:30 and 1:40, coded as 0,1 , and 2 respectively were investigated. Results indicated the maximum absorbance value $(0.3092)$ for $1: 20$ ratio. Thus 1:20 was optimum ratio to accommodate colorant from the source. 20 parts of the solvent were adequate enough for complete transfer of dye from one part of the solid dyestuff. Dynamic dye transfer equilibrium might have reached with the particular ratio. Volume greater than $20 \mathrm{ml}$ was therefore showing significantly low absorbance values. The lesser solvent volume would have been insufficient for complete transfer of dye to the solvent.

\subsection{Effect of Extraction Time:}

Figure 4 shows that time of extraction is not so significant parameter. For one hour and 2 hours of extraction, absorbance values are above mean absorbance value while absorbance value for three hours of extraction is below the mean. These absorbance values are $0.2728,0.2685$ and 0.2140 for 0,1 and 2 levels respectively. For 1 and 2 hours of extraction, the absorbance values are above the mean value of absorbance while the absorbance value for three hours of extraction is far below the mean absorbance. Therefore the optimum time for higher extraction is one hour.

\subsubsection{Effect of Assistance Method:}

Microwave pretreatment, enzyme addition and combination of both microwave and enzyme assistance were three assistance methods coded as 0,1 and 2 respectively. Results showed aspect of providing assistance is also significant for efficient extraction. Figure 4 indicated that the absorbance values are $0.2482,0.2810$ and 0.2262 for respective assistances. Absorbance in case of enzyme assistance was very well above mean absorbance value while other two methods showed their absorbance values below the mean. Therefore use of enzyme was the optimum method of assistance for extraction.

Extraction enhancement of the desired component was seen through the highest absorbance value in the enzyme method. Loosening of the structural integrity of the plant material making their cells easily breakable might be the reason releasing solutes from them, increasing the extraction yield.

\subsection{Colourant, Chemical Nature}

The results of FT-IR, UV-VIS spectroscopy and the GCMS as well support the presence of colourant of named betanin. The molecular formula and molecular weight (MW) of the colourant are $\mathrm{C} 24 \mathrm{H} 27 \mathrm{~N} 2 \mathrm{O} 13$ and $551 \mathrm{~g}$ per mole respectively. Figure 5 shows structure of the colorant. 


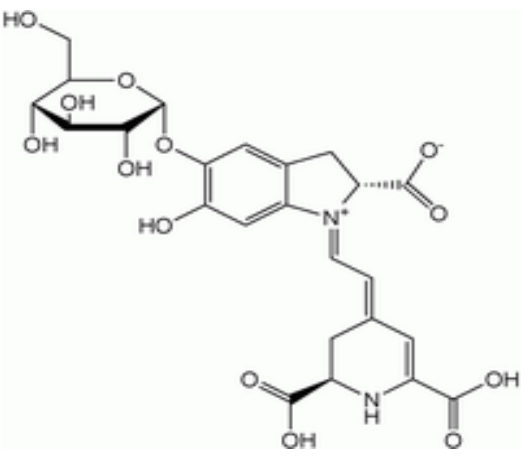

Fig 5: Structure of Betanin

\subsection{Absorbance and Dye yields Comparison and}

\section{Extraction Efficiency Enhancement}

Comparison of two experiments with respect to absorbance values was made. These values 0.255 and 0.280 were used further for yield calculations. Taguchi orthogonal array design with its subsequent ANOVA showed increase in absorbance for optimum experiment against control experiment. The comparison among the control yield and the yield obtained in the optimum extraction (Table 5 and Figure 6) shows that there is significant improvement in the extraction efficiency to about $9.80 \%$. This may be due to the collective effect of optimum conditions employed during extraction operation. Thus optimization process employed here has contributed towards enhancement in the extraction efficiency.

Table 5: Yield \& Extraction Efficiency Enhancement

\begin{tabular}{|l|l|l|l|}
\hline & \multicolumn{2}{|l|}{ Yield obtained \% } & $\begin{array}{l}\% \text { Yield } \\
\text { Improvement }\end{array}$ \\
\hline Experiment $\rightarrow$ & Control & Optimum & $\begin{array}{l}\text { Optimum over } \\
\text { control }\end{array}$ \\
\hline & 1.62 & 1.78 & 9.88 \\
\hline
\end{tabular}

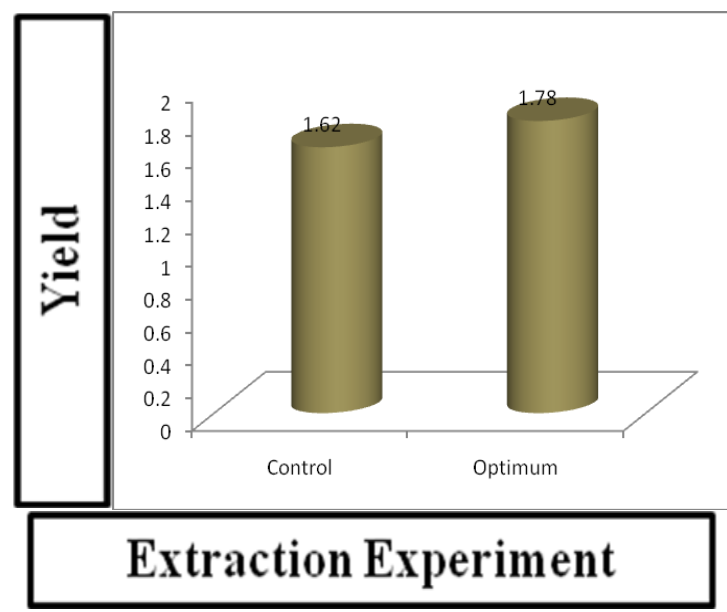

Fig 6: Yield comparison

\section{CONCLUSIONS}

Taguchi method was successfully applied to determine optimal extraction conditions. It was validated by running extraction with the optimum conditions. The particle size (150 micron), solid-liquid ratio (1:20), extraction time (one hour), assistance for extraction (enzyme treatment) were the optimum conditions. It is very much encouraging that the absorbance with the optimum conditions was higher than the control conditions. Execution of extraction as an efficient technique leading to $9.80 \%$ increase in dye yield and saving in extraction time were the outcomes of the research effort. This research can contribute to the future scale-up of Bougainvillea Glabra bracts dye production useful for textile, food, pharmaceutical and cosmetic industries. The overall research effort is also a very good example of green approach towards extraction operation in the area of natural dye production.

\section{ACKNOWLEDGEMENTS}

This work was encouraged by managements of Shivaji University Kolhapur, D.K.T.E' Textile and Institute, Ichalkaranji and T.K.I.E.T Warananagar, Maharashtra State, India. Thanks to all of them.

\section{REFERENCES}

[1]. Tiwari M.S.; Current Science; Vol. 88, No. 9, 10 May 2005; 1474-1480.

[2]. Patil P.D.; Rao C.R.; Wasif A.I.; Textile Asia; July (2012), 29-31

[3]. Gulrajani M L.; Gupta D.; Natural dyes and application to textiles, Department of textile technology, Indian Institute of Technology, New Delhi, India, (1992),

[4]. Patil P.D.; Rao C.R.; Wasif A.I.; Colourage; October (2012), 33-38

[5]. Phadke M. S.; 'Quality engineering using robust design'; 2nd edition, Pearson, (2009)

[6] Gokhale S.B.; Tatiya A.U.; Bakliwal S.R.; Fursule R.A.; Natural Product Radiance Vol.3 July-August (2004): 228-234

[7] Kothari C.R.; Research Methodology: Methods and Techniques; Second Revised Edition 2014; New Age International Publishers, New Delhi; 31-52

[8]. Sachan Kiran; Kapoor V.P.; Indian Journal of Traditional Knowledge; Vol 6(2), April (2007); 270278

[9]. Montgomery D. C.; Design and analysis of experiments; $3^{\text {rd }}$ edition, John Wiley and Sons 1991

[10]. Puri M.; Sharma D.; Barrow Colin J.; Trends in Biotechnology; January (2012), Vol. 30, No. 1; 37-44

[11]. Wilkins M.R.; Widmer W.W.; Grohmann K.; Cameron R.G.; Bioresource Technology 98 (2007); 1596-1601

[12]. Montgomery D. C.; Peck E. A.; Vining G. G.; Introduction to linear regression analysis $3^{\text {rd }}$ edition; John Wiley and Sons 2006 


\section{BIOGRAPHIES}

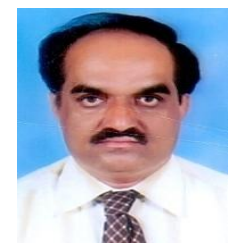

Pravinkumar D.Patil is a faculty in Chemical Engineering at the Department of Technology, Shivaji University, Kolhapur Maharashtra, India. His fields of interest are manufacture of natural products, green chemistry and green technology.

Professor Dr. C.R.Rao is the Director Evaluation, at Vignan University, Guntur, Andhra Pradesh, India. He is basically a Chemical Engineer with 30 years of experience in academics.

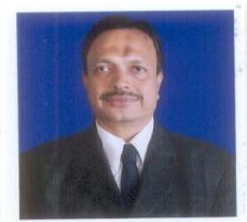

Dr.Wasif A.I. is an eminent Professor at D.K.T.E'S Textile and Engineering Institute, Ichalkaranji, Maharashtra, India Eco friendly Textile processing, BioTechnology applications to textile processing, Technical Textiles and Textile

Processing Effluent Treatments are his research areas.

J.R.Nagla, is a statistician and a faculty at D.K.T.E'S Textile and Engineering Institute, Ichalkaranji, Maharashtra, India. He has very good expertise for the application of statistics in textile industry and academic research. 